\title{
Pengaruh Jenis Zeolit Terhadap Sensitivitas Sensor Non-Enzimatik untuk Mendeteksi Glukosa
}

\author{
Febriati Nanda*, Dwi Puryanti, Afdhal Muttaqin \\ Jurusan Fisika, FMIPA Universitas Andalas, Padang \\ Kampus Unand Limau Manis, Pauh Padang 25163 \\ *febriatinanda@yahoo.co.id
}

\begin{abstract}
ABSTRAK
Sensor gukosa non-enzimatik dengan modifikasi zeolit sintetis telah dibuat. Pada penelitian ini digunakan zeolit dengan kandungan Sodalit, Lezurit, Megakalsilit, dan Nosean yang ditambahkan dalam campuran grafit dan paraffin. Elektroda pasta karbon (EPK) dibuat dengan komposisi grafit: paraffin sebesar $50 \mathrm{mg}$ : $70 \mathrm{mg}$. Elektroda pasta karbon termodifikasi zeolit (EPKZ) dibuat dengan komposisi grafit: paraffin: zeolit sebesar $50 \mathrm{mg}$ : $30 \mathrm{mg}$ : $20 \mathrm{mg}$. Kinerja elektroda (sensitivitas, linieritas dan tingkat reversibilitas elektroda) diuji menggunakan metode cyclic voltammetry (CV). Hasil pengujian diperoleh elektroda EPKZ2 dengan fraksi zeolit $100 \%$ menghasilkan nilai sensitivitas tertinggi sebesar $15,302 \mu \mathrm{Acm}^{-2} \mathrm{mM}^{-1}$. Daerah optimum pendeteksian yang dicirikan dengan linieritas keluaran sensor berada pada rentang konsentrasi $50 \mathrm{mg} / \mathrm{dl}-300 \mathrm{mg} / \mathrm{dl}$. Scan rate efektif dilakukan sebesar $100 \mathrm{mV} / \mathrm{s}$ dan nilai kesalahan puncak oksidasi elektroda sebesar 19,16\% lebih kecil dari standar minimum sensor glukosa.

Kata kunci: sensor non-enzimatik, zeolit sintetis, sensitivitas, linieritas, reversibilitas.
\end{abstract}

\section{ABSTRACT}

The non-enzymatic glucose sensor with made of synthetic zeolite has been formed. The sensor electrode was made from zeolite containing sodalit, lezurit, megakalsilit, and nosean that was added into the mixture of graphite and paraffin. Carbon paste electrode (EPK) was made from graphite and paraffin with a ratio of $50 \mathrm{mg}$ : $70 \mathrm{mg}$. The zeolite modified carbon paste (EPKZ) was made from graphite: paraffin: zeolite with a ratio of $50 \mathrm{mg}: 30 \mathrm{mg}: 20 \mathrm{mg}$. Electrode performance (sensitivity, linearity and measurement reversibility) was tested using cyclic voltammetry $(\mathrm{CV})$ method. The result of the test obtained by electrode EPKZ2 with $100 \%$ zeolite fraction yield sensitivity value of $15,302 \mu \mathrm{Acm} \mathrm{mm}^{-1}$. The glucose sensor detects accurately for glucose sensor within the concentration range of $50 \mathrm{mg} / \mathrm{dl}$ $300 \mathrm{mg} / \mathrm{dl}$. An effective scan rate of $100 \mathrm{mV} / \mathrm{s}$ and electrode oxidation peak error rate of 19,16\% small than the minimum standars of glucose sensors.

Keywords: non-enzymatic sensor, synthetic zeolite, sensitivity, linearity, reversibility.

\section{PENDAHULUAN}

Saat ini banyak dikembangkan sensor glukosa non-enzimatik (Toghill dan Compton, 2010). Sensor non-enzimatik diharapkan dapat memperbaiki dan meningkatkan kinerja sensor enzimatik yang menggunakan pengenal hayati seperti enzim, mikroba, dan jaringan (Reitz, dkk., 2008). Atom memiliki peran utama pada proses oksidasi glukosa sensor non-enzimatik yang dapat mendeteksi pada permukaan secara langsung (Pletcher, 1984). Karakteristik minimum yang menjadi syarat kelayakan sebuah sensor glukosa yang diatur oleh International Organization for Standardization (ISO) ditampilkan pada Tabel 1.

Tabel 1 Karakteristik minimum sensor glukosa

\begin{tabular}{ll}
\hline \multicolumn{1}{c}{ Properti } & \multicolumn{1}{c}{ Alasan dan / atau diperlukan respon minimum } \\
\hline Selektivitas & $\begin{array}{l}\text { Harus selektif mendeteksi glukosa saja, meskipun diberi minimal } \\
\text { gangguan dari sumber lain. }\end{array}$ \\
\hline Sensitivitas & $1 \mu \mathrm{Am}^{-2} \mathrm{mM}^{-1}$ atau lebih besar untuk memperbaiki sensor enzimatik \\
\hline $\begin{array}{l}\text { Tidak ada ketergantungan } \\
\text { oksigen }\end{array}$ & $\begin{array}{l}\text { Ketergantungan pada oksigen merupakan masalah utama bagi sistem } \\
\text { GOD (Glucose } \text { Oxidase })\end{array}$ \\
\hline Stabilitas & Stabil selama aplikasi dan memiliki masa hidup/pakai melebihi 6 bulan \\
\hline Akurasi dan presisi & Harus memenuhi standar ISO dengan error 20\%, 95\% dari waktu \\
\hline Biokompatibilitas & $\begin{array}{l}\text { Khususnya untuk penggunaan } \text { in-vivo karena komponen biologis dan } \\
\text { respon imun }\end{array}$ \\
\hline Biaya fabrikasi & Biaya fabrikasi dan biaya operasional harus lebih rendah \\
\hline Mudah fabrikasi & Mudah difabrikasi yang dicetak pada layar strip elektroda enzimatik \\
\hline
\end{tabular}


Bahan elektroda pada sensor glukosa non-enzimatik sangat menentukan kinerja sensor yang dihasilkan. Keberhasilan elektroda yang digunakan terletak pada kemampuannya dalam menyeleksi aktivitas ion secara spesifik dalam larutan. Oleh karena itu, dilakukan pemodifikasian menggunakan bahan lain sehingga dapat menghasilkan pembacaan yang lebih tinggi dan akurat. Salah satu bahan yang dapat dimanfaatkan sebagai penyeleksi ion atau katalis berdasarkan sifat materialnya yaitu zeolit (Toghill dan Compton, 2010).

Zeolit adalah material berpori yang disebut moleculer sieve (saringan molekuler) karena memiliki pori-pori yang berukuran molekuler. Struktur dan kerangka zeolit yang berpori membuat zeolit memiliki banyak kegunaan diantaranya sebagai adsorben, penukar kation, sensor gas, katalis dan penyaring molekul (Ahkam, 2011). Kemampuan zeolit dapat secara efektif bekerja juga bergantung pada kandungan fraksinya (tingkat kemurniannya) (Nurhabibah, 2017), rasio Si/Al (Yuliusman, dkk., 2013), struktur kristalnya dan lain-lain. Pori-pori zeolit memiliki kemampuan untuk menangkap dan mentransfer ion melalui media lipofilik, bersifat selektif, dan dapat membedakan ukuran ion-ion (Ramadhani, dkk., 2006). Zeolit pada sensor glukosa berfungsi sebagai molekul pengenal yang terintegrasi pada elektroda. Saat pendeteksian, elektroda menghasilkan arus (Tribidasari dan Ivandini, 2006). Arus puncak yang terlihat pada voltammogram hasil pengukuran cyclic voltammetry $(\mathrm{CV})$ ketika tegangan input divariasikan. Munculnya arus puncak memberikan informasi bahwa pendeteksian glukosa telah berhasil dilakukan.

Sari (2012) mensintesis dan mengkarakterisasi komposit zeolit-glass carbon sebagai zeolit modified electrode (ZME) untuk indikator gula asam askorbat. Elektroda yang termodifikasi jenis zeolit faujasit (FAU) telah mampu mendeteksi pada konsentrasi 0,001 M dengan puncak oksidasi pada $+0,3$ V. Selanjutnya, Puspitasari (2012) membuat dua jenis elektroda yaitu elektroda pasta karbon termodifikasi zeolit (EPKZ) dan zeolit-asetilpiridin (EPKZA) untuk mendeteksi ion kromium (III). Hasil pendeteksian menunjukkan elektroda modifikasi zeolit-asetilpiridin komposisi massa $20 \mathrm{mg}$ (EPKZA20) lebih baik dalam pendeteksian ion kromium dengan dihasilkan arus optimum 2,46 $\mu \mathrm{A}$. Nilai arus semakin meningkat jika dibandingkan dengan EPKZ sebesar 0,01 $\mu \mathrm{A}$.

Pada penelitian ini dilakukan pemodifikasian elektroda menggunakan kandungan beberapa zeolit sintetis dari hasil abu dasar batubara. Variasi waktu peleburan alkali hidrotermal (Nurhabibah, 2017) menghasilkan jenis zeolit sodalit, lezurit, megakalsilit, dan nosean. Metode CV yang digunakan dimana pengujian elektroda dilakukan di dalam beberapa konsentrasi larutan glukosa. Pembacaan puncak arus oksidasi yang dihasilkan dengan variasi konsentrasi, tentunya menunjukkan respon semakin meningkat juga.

\section{METODE}

Untuk melakukan pengukuran CV perlu dilakukan beberapa persiapan diantaranya, pembuatan elektroda pembanding $\mathrm{Ag} / \mathrm{AgCl}$, pembuatan elektroda pasta karbon (EPK/EPKZ), dan elektroda pendukung yang berasal dari buatan pabrik. Penelitian dilakukan di Laboratorium Fisika Material Unand.

\subsection{Pembuatan elektroda pembandig Ag/AgCl}

Pembuatan elekroda $\mathrm{Ag} / \mathrm{AgCl}$ menggunakan kawat perak sepanjang $14 \mathrm{~cm}$ yang telah dipotong menjadi 2 bagian masing-masing $7 \mathrm{~cm}$. Kawat dililit dengan tembaga sebagai penghantar arus. Selanjutnya, dilakukan pelapisan dengan metode elektrokimia menggunakan $50 \mathrm{ml}$ larutan $\mathrm{KCl} 1 \mathrm{M}$ yang diberi tegangan 1,5 V. Waktu pelapisan berlangsung 1,5 menit dan akan menghasilkan endapan hitam pada perak berkutub (+) seperti ditampilkan pada Gambar 1. 


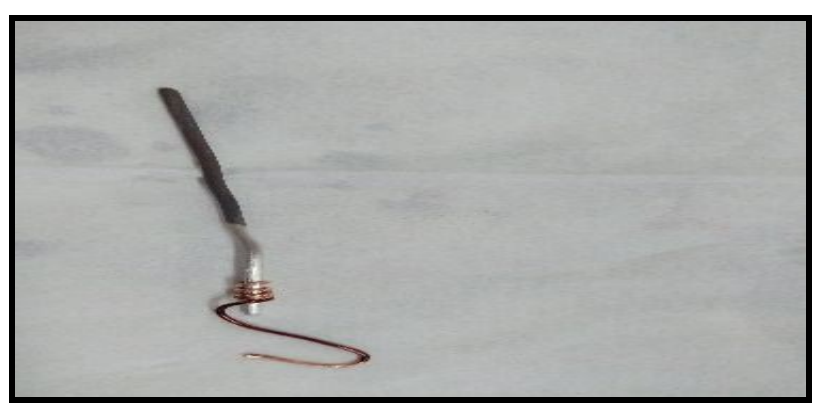

Gambar 1 Kawat Ag yang telah dilapisi.

\subsection{Pembuatan elektroda kerja EPK dan EPKZ}

Bahan yang digunakan untuk pembuatan elektroda kerja adalah grafit $70 \mathrm{mg}$ dan paraffin $30 \mathrm{mg}$ untuk jenis EPK. Sedangkan untuk EPKZ perbandingan komposisi bahan yaitu grafit $50 \mathrm{mg}$, paraffin $30 \mathrm{mg}$, dan zeolit $20 \mathrm{mg}$. Adapun kandungan fraksi zeolit dalam persentase pada tiap jenisnya ditunjukkan dalam Tabel 2. Seluruh bahan dicampur dalam wadah dan diletakkan di atas magnetic stirrer bersuhu $60{ }^{\circ} \mathrm{C}$. Bahan yang telah homogen dimasukkan setinggi $0,5 \mathrm{~cm}$ pada bagian bawah tabung kaca berdiameter $0,3 \mathrm{~cm}$. Kawat tembaga sebagai penghubung elektroda, dimasukkan ke dalam tabung agar dapat menempel pada bahan.

Tabel 2 Persentase fraksi zeolit sintesis pembuatan elektroda EPK dan EPKZ

\begin{tabular}{lrcc}
\hline No & Nama & Jenis zeolit & \% Fraksi \\
\hline 1 & EPK & Tidak ada & 0 \\
\hline 2 & EPKZ1 & Sodalit $(2,7 \%)$, Lezurit $(47 \%)$, dan Megakalsilit $(6,6 \%)$, & 56,3 \\
\hline 3 & EPKZ2 & Sodalit $(43,1 \%)$, Leusit $(34,7 \%)$ dan Kalsilit $(22,2 \%)$ & 100 \\
\hline 4 & EPKZ3 & Sodalit $(66,6 \%)$ & 66,6 \\
\hline 5 & EPKZ4 & Sodalit $(7,1 \%)$ dan Nosean $(56,9 \%)$ & 64 \\
\hline
\end{tabular}

\subsection{Karakterisasi menggunakan CV}

Kinerja sensor diuji menggunakan metode $\mathrm{CV}$ dengan melakukan input tegangan dalam program Echem sehingga akan menghasilkan arus terbaca. Ketiga elektroda disusun dalam gelas piala seperti pada Gambar 2 dan kemudian wadah diisi larutan glukosa konsentrasi 50, 100, 200, 300, 400, dan $500 \mathrm{mg} / \mathrm{dl}$. Hasil pendeteksian menghasilkan grafik voltammogram yang berarti siklus oksidasi dan reduksi larutan telah berlangsung. Nilai maksimal dan data yang diambil sebagai pembacaan adalah nilai arus puncak oksidasi pada voltammogram.

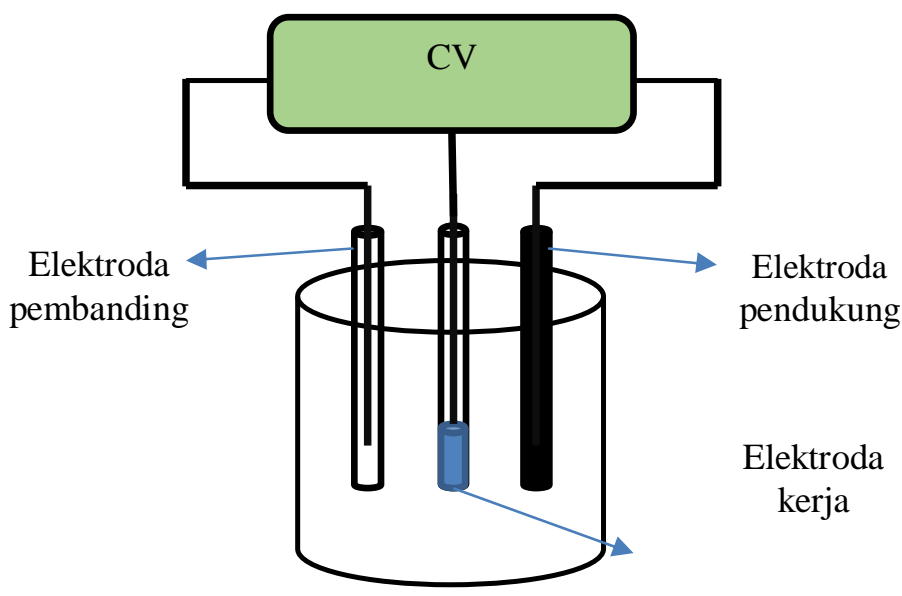

Gambar 2 Skema cyclic voltammetry

\section{HASIL DAN DISKUSI}

Pengukuran kinerja elektroda dengan melakukan variasi konsentrasi larutan glukosa telah ditampilkan dalam voltammogram. Voltammogram semua elektroda memperlihatkan 
adanya respon saat menyeleksi ion-ion dalam larutan glukosa yang ditunjukkan munculnya arus puncak oksidasi. Hasil voltammogram menggunakan jenis elektroda yang berbeda juga mampu menunjukkan puncak arus oksidasi. Puncak oksidasi terjadi ketika larutan glukosa mengalami proses oksidasi

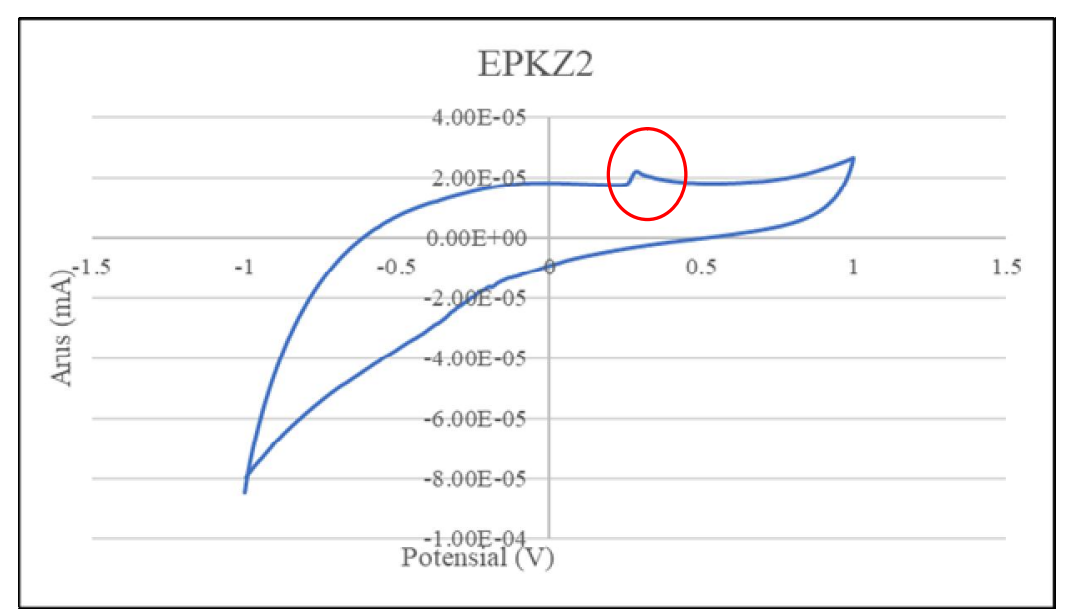

Gambar 3 Voltammogram EPKZ2 pada konsentrasi $50 \mathrm{mg} / \mathrm{dl}$

Gambar 3 menunjukkan voltammogram pada konsentrasi $50 \mathrm{mg} / \mathrm{dl}$. Terjadinya arus puncak oksidasi mengindikasikan bahwa larutan glukosa telah mengalami oksidasi dengan terurainya $\mathrm{CO}_{2}$ dan $\mathrm{H}_{2} \mathrm{O}$. Molekul air yang terkandung di dalam larutan glukosa mengalami ionisasi membentuk ion $\mathrm{H}^{+}$dan $\mathrm{OH}^{-}$Ion $\mathrm{OH}^{-}$(hidroksil) yang memiliki kelebihan elektron bebas akan terdeteksi oleh elektroda. Reaksi oksidasi glukosa memenuhi Persamaan 1 dan 2.

$$
\begin{gathered}
\mathrm{C}_{6} \mathrm{H}_{12} \mathrm{O}_{6(\mathrm{aq})}+6 \mathrm{O}_{2(\mathrm{~g})} \rightarrow 6 \mathrm{CO}_{2(\mathrm{~g})}+6 \mathrm{H}_{2} \mathrm{O}_{(\mathrm{l})} \\
2 \mathrm{H}_{2} \mathrm{O} \rightarrow 2 \mathrm{H}^{+}+2 \mathrm{OH}^{-}
\end{gathered}
$$

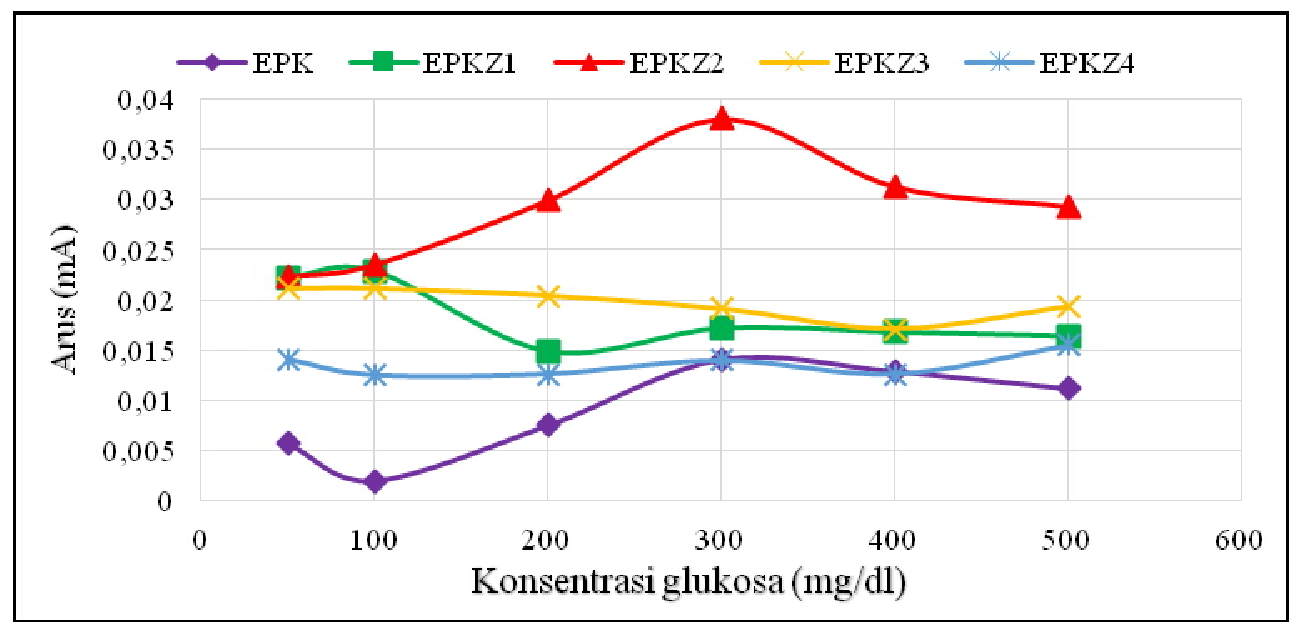

Gambar 4 Arus terdeteksi sebagai fungsi konsentrasi glukosa

Kemampuan elektroda dalam membaca konsentrasi yang berbeda dapat dilihat pada Gambar 4. Terlihat bahwa semua elektroda menunjukkan respon arus terhadap konsentrasi yang diberikan, namun arus terukur belum menunjukkan pola yang linier. Hal ini dapat dilihat dari pola sebaran data dimana peningkatan konsentrasi tidak sebanding dengan nilai arus yang dihasilkan. Elektroda EPKZ2 menghasilkan respon yang meningkat signifikan pada konsentrasi $50 \mathrm{mg} / \mathrm{dl}$ sampai $300 \mathrm{mg} / \mathrm{dl}$. Tingginya respon EPKZ2 kemungkinan besar dikarenakan sampel ini memilikifraksi zeolit $100 \%$ sehingga kemampuan mendeteksi lebih besar. Ketika konsentrasi glukosa dinaikkan hingga di atas $300 \mathrm{mg} / \mathrm{dl}$ arus oksidasi makin mengecil. Hal ini 
dapat disebabkan karena elektroda telah jenuh untuk mendeteksi serta kurangnya supply oksigen.

Linieritas respon pada elektroda EPKZ2 menunjukkan kemampuan optimum pendeteksian $50 \mathrm{mg} / \mathrm{dl}$ hingga $300 \mathrm{mg} / \mathrm{dL}$ pada Gambar 5. Nilai sensitivitas ditunjukkan dari kemiringan slope sebesar $6.10^{-5} \mathrm{~mA} / \mathrm{mgdl}^{-1}$, selanjutnya dikonversi berdasarkan satuan ISO dan didapatkan $15,302 \mu \mathrm{Acm}^{-2} \mathrm{mM}^{-1}$. Nilai tersebut telah berada di atas nilai minimum syarat sensor glukosa pada Tabel 1. Demikian diperoleh jenis elektroda EPKZ2 yang dapat dijadikan rujukan dalam pembuatan material sensor.

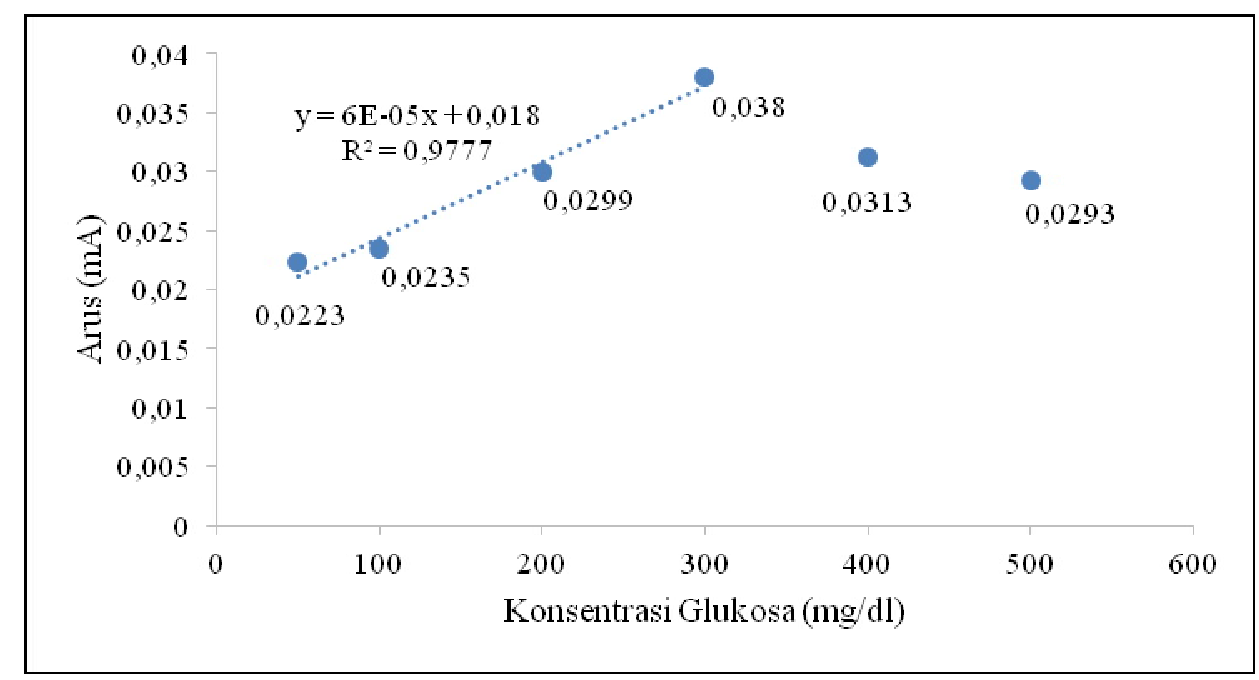

Gambar 5 Perbandingan arus terdeteksi terhadap variasi konsentrasi glukosa pada elektroda EPKZ2

Variasi scan rate juga dilakukan untuk melihat arus yang dihasilkan terhadap laju pindai yang diberikan. Pengaruh peningkatan scan rate memberikan pembacaan arus yang semakin meningkat juga, namun pada laju yang besar terkadang pendeteksian tidak efektif. Oleh sebab itu, pada penelitian ini diperoleh laju yang efektif untuk mendeteksi sebesar 100 $\mathrm{mV} / \mathrm{s}$, karena munculnya puncak oksidasi telah terlihat untuk setiap elektroda.

Pendeteksian pada elektroda EPKZ2 dilakukan sebanyak lima kali pengulangan untuk mengetahui presisinya (reversibilitas). Voltammogram pada Gambar 6 menunjukkan lima kali pengulangan yang memiliki standar deviasi $5,25 \times 10^{-6} \mathrm{~mA}$ dengan kesalahan relatif 1,46 , sedangkan presisi untuk elektroda sebagai sensor hanya menggunakan data dari nilai puncak oksidasi. Bahwa dalam lima kali pengulangan diperoleh nilai pembacaan rata-rata arus puncak osidasi $50 \mathrm{mg} / \mathrm{dl}$ sebesar $0,0257 \mathrm{~mA}$ dengan kesalahan relatif sebesar $19,16 \%$. Nilai ini berdasarkan ISO ternyata berada dibawah nilai syarat minimum sensor. Ini menunjukkan bahwa elektroda EPKZ2 telah memenuhi beberapa kriteria untuk dijadikan sebuah sensor.

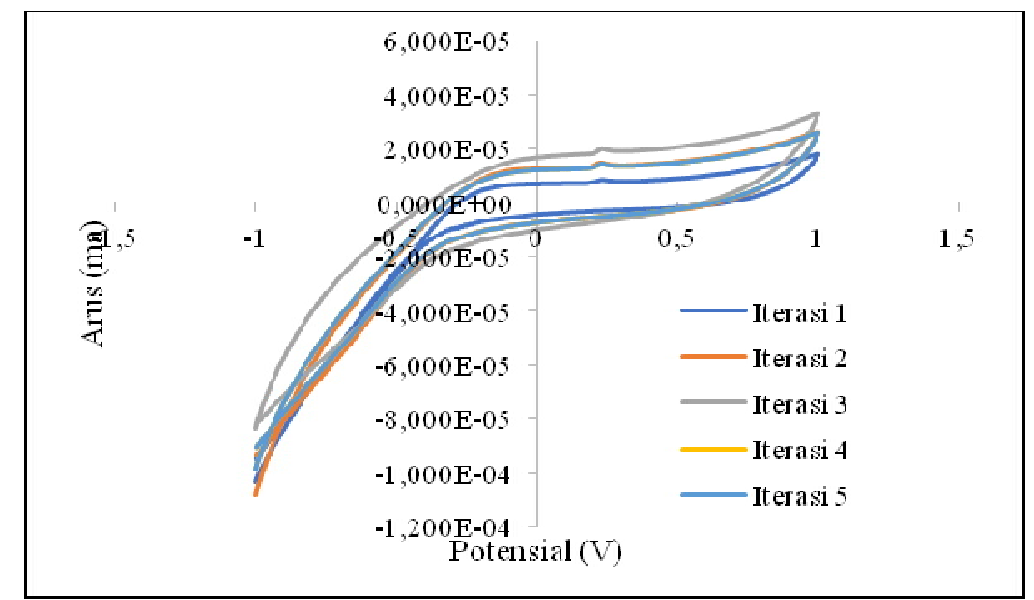

Gambar 6 Voltammogram elektroda EPKZ2 dalam 5 kali pengulangan 


\section{KESIMPULAN}

Berdasarkan hasil dan pembahasan dapat disimpulkan, elektroda EPKZ2 dengan pemodifikasian jenis zeolit fraksi $100 \%$ (Sodalit, Leusit, Kalsilit) menunjukkan pendeteksian lebih optimum yang dilakukan pada konsentrasi $50 \mathrm{mg} / \mathrm{dl}$ sampai $300 \mathrm{mg} / \mathrm{dl}$. Nilai sensitivitas, linieritas, dan presisi elektroda telah memenuhi karakteristik minimum sensor glukosa.

\section{DAFTAR PUSTAKA}

Ahkam, M., "Sintesis dan Karakterisasi Membran Nanozeolit Y untuk Aplikasi Pemisahan Gas Metanol-Etanol", Skripsi, Universitas Indonesia, (2011).

Nurhabibah, "Pengaruh Waktu Peleburan Terhadap Konduktivitas Listrik Zeolit Sintetis dari Abu dasar Batubara dengan Metode Peleburan Alkali Hidrotermal", Skripsi, Universitas Andalas, (2017).

Pletcher, D., "Electrocatalysis: Present and Future", Journal of Applied Elecrochemistry, Vol.14, No.4, hal. 403-415, (1984).

Puspitasari, I., "Pembuatan elektroda pasta karbon termodifikasi zeolit dan zeolit - asetilpiridin sebagai elektroda selektif ion kromium(III)", Skripsi, Institut Pertanian Bogor, (2012).

Ramadani., Siswanta, D., Jumina, "Pemanfaatan Tetraksi (N-ropildihidro oxazina)-C-metil Kaliks (4) Resorsinarena Sebagai Komponen Membran Elektrode Selektif Ion Perak", Jurnal Sains dan Sibernatika, Vol.19, hal. 243-256, (2006).

Reitz, E., Jia,W., Gentile.M., Wang,Y., Lei,Y., "CuO nanospheres based non-enzymatic glucose sensor", International Journal of Nanomedicine, Vol. 20, hal. 2482-2486, (2008).

Sari, W.P., "Sintetsis dan Karakterisasi Komposit Zeolite-Glass Carbon dan Aplikasinya sebagai Zeolit Modified Electrode (ZME) Untuk Indikator Asam Askorbat", Skripsi, Universitas Indonesia, (2012).

Tribidasari, A. dan Ivandini, "Electrochemical Detection of Arsenic (III) Using IridiumImplanted Boron-Doped Diamond Electrodes", Journal Analytical Chemistry, Vol. 78, hal. 6291-6298, (2006).

Toghill, E.K. dan Richard G.C., "Electrochemical Non-enzymatic Glucose Sensors: A Perspective and an Evaluation", International Journal of Electrochemical Science, Vol. 5, hal. 1246-1301, (2010).

Yuliusman., Widodo, W.P., Yulianto, S.N., "Pemilihan Adsorben untuk Penjerapan Karbon Monoksida Menggunakan Model Adsorbsi Isotermis Langmuir", Jurnal Reaktor, Vol.14 No3, hal.225-233, (2013). 